\title{
Development of peanut paneer from the admixture of peanut milk and skimmed milk
}

\author{
J. DAVID
}

\begin{abstract}
An investigation was carried out with an attempt to develop Peanut Paneer by partial addition of Peanut milk and skim milk. For control, $\left(\mathrm{T}_{0}\right)$ Peanut milk was standardized to 6 per cent fat and 9 per cent $\mathrm{SNF}$ and treatment $\left(\mathrm{T}_{1}\right)$ was standardized to a ratio of 50:50 (PM:SM), $\mathrm{T}_{2}$ 60:40 (PM:SM) and $\mathrm{T}_{3}$ (70:30) (PM:SM). The peanut paneer samples of different treatments were analyzed for physicochemical properties (moisture, protein, fat, carbohydrate and ash), its nutritional content and organoleptic characteristics (colour and appearance, body and texture, flavour and taste) by trained panelist using 9 point hedonic scale. Microbiological analysis was carried out to assess the shelflife of the best treatments by SPC and coliform test. Analysis revealed that the product conform to the legal standard as per PFA. Thus, as far as product acceptability judged by organoleptic evaluation and therapeutic value, the treatment can be $\operatorname{rated}$ as $T_{2}>T_{1}>T_{0}>T_{3}$.
\end{abstract}

KEY WORDS : Peanut milk, Skimmed milk, Peanut Paneer

How TO CITE THIS PAPER : David, J. (2014). Development of peanut paneer from the admixture of peanut milk and skimmed milk. Res. J. Animal Hus. \& Dairy Sci., 5(2) : 113-115. 